\title{
Pathogenesis of renal failure in cirrhosis and fulminant hepatic failure
}

\author{
S. P. Wilkinson \\ B.Sc., M.B., M.R.C.P. \\ D. Hurst \\ B.Sc.
}

\author{
B. PortmanN \\ M.D.
}

ROGER WILliams

M.D., F.R.C.P.

The Liver Unit and Department of Chemical Pathology, King's College Hospital, London S.E.5

\section{Summary}

Acute renal failure in cirrhosis and fulminant hepatic failure represents a spectrum with 'functional renal failure' at one end and acute tubular necrosis at the other. In fulminant hepatic failure the development of renal failure is not necessarily a measure of the severity of liver damage.

Functional renal failure is due to active renal vasoconstriction which may, at least in fulminant hepatic failure, be initiated by systemic endotoxaemia.

\section{Introduction}

Renal failure is common in advanced cirrhosis. In the series of Shear, Kleinerman and Gabuzda (1965), $84 \%$ of patients dying of cirrhosis in hepatic coma had renal failure as evidenced by an elevated blood urea nitrogen level. It is also common in fulminant hepatic failure; seventy-three of 100 consecutive cases seen at King's College Hospital who progressed to grade III or IV hepatic encephalopathy have had this complication (glomerular filtration rate $<15 \mathrm{ml} / \mathrm{min}$ or $24 \mathrm{hr}$ urine volume $<400 \mathrm{ml}$ with plasma creatinine concentration $>2 \mathrm{mg} / 100$ $\mathrm{ml})$. The development of renal failure was associated with a poor prognosis in that seventy-two of the seventy-three cases died, there being seventy-nine deaths in the complete series.

The renal failure of cirrhosis is usually associated with intact tubular function and therefore often referred to as 'functional renal failure' (FRF) (Vesin, 1962), but features of acute tubular necrosis may be present terminally (Shear et al., 1965). Both types of renal failure may also be seen in fulminant hepatic failure, acute tubular necrosis often being preceded by functional renal failure (Wilkinson, Blendis and Williams, 1974b; Wilkinson et al., 1974a).

\section{Evidence for 'functional' nature of renal failure}

Histologically the kidneys are usually normal in cases of functional renal failure (Vesin, 1962; Wilkinson et al., 1974b). However, renal histology may be difficult to interpret when jaundice is present since histological evidence of tubular necrosis, often associated with bile casts, may be present without impairment of renal function (Papper and Vaamonde, 1971). A low urinary sodium concentration is often considered as evidence of intact tubular function in FRF, but this could also result from the influence of hyperaldosteronism on 'intact nephrons' whilst the remaining nephrons were necrotic and not functioning.

The measurement of urinary lysozyme (muramidase) concentration might be a better index of tubulars integrity. Lysozyme, a low molecular weight protein, synthesized by leucocytes, is filtered by the glomerulus. Normally it is almost completely resorbed by the proximal tubules and its presence in the urine has been shown to be a good index of tubular damage (Hayslett, Perillie and Finch, 1968). We have found normal urinary lysozyme concentrations in nineteen of thirty-seven patients with renal failure, associated with fulminant hepatic failure or cirrhosis, indicative of intact tubular function in these nineteen patients, the other eighteen patients having elevated urinary lysozyme levels. The nineteen patients with normal urinary lysozyme levels all had a urine sodium concentration of $<12 \mathrm{mEq} / \mathrm{l}$ whereas those with marked elevations all had a urine sodium concentration of $>12 \mathrm{mEq} / \mathrm{l}$, confirming the validity of the use of the urine sodium as an index of tubular integrity in such patients. The presence of casts in the urine sediment correlated poorly with urinary lysozyme levels. In both fulminant hepatic failure and cirrhosis a continuous range of urinary lysozyme concentrations was found from undetectable to grossly elevated, suggesting a complete spectrum of renal failure with FRF at one end and acute tubular necrosis at the other.

Relation of hepatocellular damage to renal failure in fulminant hepatic failure

In cirrhosis it is often stated that the occurrence of 
renal failure is a reflection of the severity of the hepatocellular failure. Recently we have examined, in sixty-four patients dying of fulminant hepatic failure, the relationship between renal failure and the amount of surviving liver tissue. The latter was assessed morphometrically in liver biopsies, taken within half an hour of death, and expressed as the 'hepatocyte volume fraction' (HVF) which is the ratio of the area of surviving hepatocytes to total area in the histological section. All patients had a reduced HVF, the highest value being $54 \%$ (normal $85 \%$ ). In patients who developed renal failure as a preterminal event in the last $24 \mathrm{hr}$ of life, the HVF was similar to that found in the cases without renal failure (Fig. 1). However, the patients who developed renal failure before this and in whom this was an important part of the illness, had a higher mean HVF than

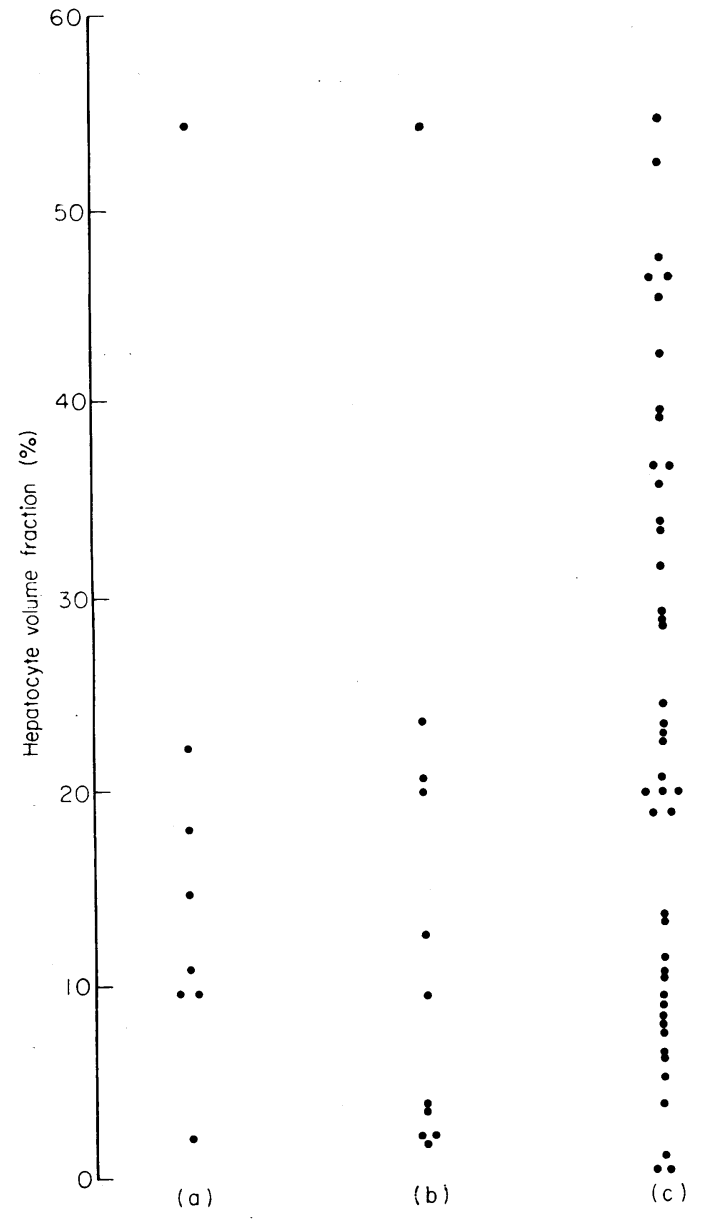

Fig. 1. Relation of hepatocyte volume fraction to renal failure in fulminant hepatic failure. (a) No renal failure; (b) renal failure developing in last day of life; (c) nonterminal renal failure. those without renal failure, though the difference was not statistically significant. Thus, in fulminant hepatic failure, renal failure would not appear to be a reflection of the severity of the hepatocellular destruction.

\section{Pathogenic factors}

FRF may be precipitated by a number of factors including gastrointestinal haemorrhage, infection, and paracentesis abdominis (Shear et al., 1965). Equally frequently it may arise spontaneously. A separate entity, diuretic-induced uraemia, should not be confused with functional renal failure, Liebermann and Reynolds (1966) having drawn attention to the differences between these two types of renal lesion.

To the nephrologist functional renal failure is a form of pre-renal uraemia and theoretically could arise as a result of hypotension, decreased cardiac output or a depleted plasma volume. However, when it occurs with hypotension, renal failure usually precedes this. Lancestremere et al. (1962) and McCloy et al. (1967) have shown that the cardiac index and plasma volume are often elevated in association with FRF in cirrhosis. Furthermore, plasma expansion has only poor and inconsistent effects on renal func- 8 tion in this situation (Reynolds, Liebermann and Redeker, 1967). The results in our patients with fulto minant hepatic failure and functional renal failure are shown in Fig. 2, and values were always within the normal range or elevated. Although total plasma volume may be elevated in cirrhosis with functional renal failure, it has been suggested that the 'effective plasma volume' may be decreased because of pooling of blood in the splanchnic circulation. Schroeder, Numann and Chamberlain (1970) reported one case of cirrhosis with FRF in whom dramatic improvement in renal function occurred following a portasystemic shunt, a procedure that should reverse 'splanchnic pooling'. However, others have not had this experience (Garrett, Vorhees and Sommers, 1970) and the intravenous reinfusion of concentrated ascitic fluid, another procedure that should correct a depleted effective plasma volume, also usually fails to improve renal function in such patients (Levy, 1972).

Renal arteriograms (Epstein" et al., 1970) have shown that the mechanism of the functional renal failure of cirrhosis is a profound vasoconstriction involving the major branches of the main renal artery and intrarenal vessels. It is unlikely that this is a result of overactivity of the sympathetic nervous system since infusions of phentolamine into the renal artery failed to reverse the vasoconstriction. Endotoxins are powerful renal vasoconstrictor substances (Cavanagh et al., 1970) and their role in the pathogenesis of renal failure in fulminant hepatic failure has been investigated (Wilkinson et al., 1974a). 


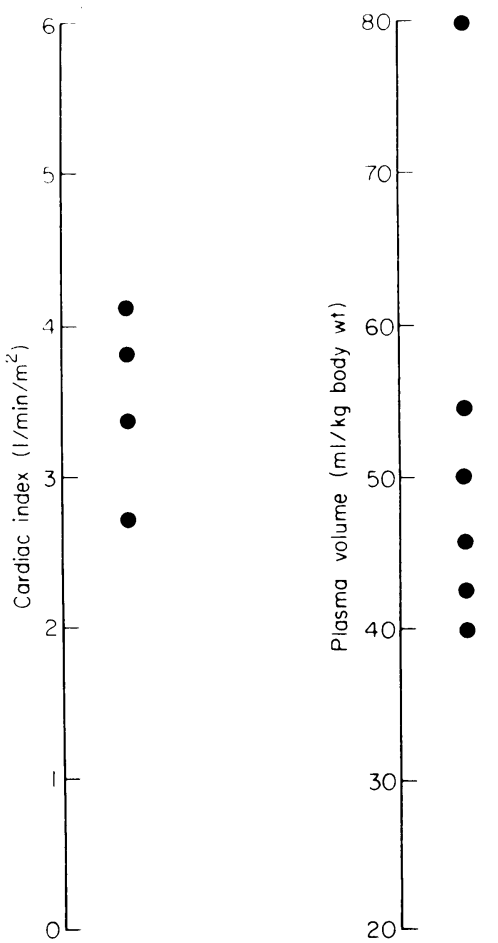

FIG. 2. Cardiac index and plasma volume in FRF associated with fulminant hepatic failure (normal value: cardiac index $2 \cdot 5-3 \cdot 71 / \mathrm{min} / \mathrm{m}^{2}$, plasma volume $34-48$ $\mathrm{ml} / \mathrm{kg}$ body $\mathrm{wt}$ ).

Systemic endotoxaemia was determined using the Limulus assay (Levin, Tomasulo and Oser, 1970). All patients with a glomerular filtration rate of less than $25 \mathrm{ml} / \mathrm{min}$ had endotoxaemia, whereas this could not be detected in patients with a glomerular filtration rate of greater than $40 \mathrm{ml} / \mathrm{min}$. Serial studies in two patients showed that renal failure developed shortly after endotoxaemia was first detected. The results have been confirmed by Wardle (1974). No other evidence of Gram-negative infection was found in most patients in the series and it was concluded that the endotoxaemia was due to impaired hepatic clearance of that normally absorbed from the bowel into the portal circuration. Both varieties of renal failure were seen in relation to endotoxaemia but six of nine patients with functional renal failure subsequently developed acute tubular necrosis.

These studies have been extended to ten patients with functional renal failure and cirrhosis. In only one case was there a strongly positive limulus assay (equivalent to an endotoxin concentration of $>2$ $\mathrm{ng} / \mathrm{ml})$, five were weakly positive $(0 \cdot 2-2 \mathrm{ng} / \mathrm{ml})$ and the other four, negative $(<0.2 \mathrm{ng} / \mathrm{ml})$. These results are clearly inconclusive, but it may be that amounts of endotoxin capable of causing renal vasoconstric- tion are not always detected by this assay. However, in patients without liver disease endotoxaemia is usually associated with acute renal failure with tubular necrosis, and none of these ten patients developed this renal lesion.

\section{Acknowledgments}

We would like to express our thanks to Miss Helen Moodie, and to Drs V. Arroyo, W. Clark and V. Parsons for their help and advice during these studies.

\section{References}

Cavanagh, D., Rao, P.S., Sutton, D.M.C., Bhagat, B.D. \& BachmanN, F. (1970) Pathophysiology of endotoxin shock in the primate. American Journal of Obstetrics and Gynecology, 108, 705.

Epstein, M., Berk, D.P., Hollenberg, N.K., Adams, D.F., Chalmers, T.C., Abrams, H.L. \& Merrill, J.P. (1970) Renal failure in the patient with cirrhosis: the role of active vasoconstriction. American Journal of Medicine, 49, 175.

Garrett, J.G., Voorhees, A.B. \& Sommers, S.C. (1970) Renal failure following portasystemic shunt in patients with cirrhosis of the liver. Annals of Surgery, 172, 218.

Hayslett, J.P., Perillie, P.E. \& Finch, S.C. (1968) Urinary muramidase and renal disease. New England Journal of Medicine, 279, 506.

Lancestremere, R.G., Davidson, P.L., EARley, L.E., O'Brien, F.J. \& PAPper, S. (1962) Renal failure in Laennec's cirrhosis. II. Simultaneous determination of cardiac output and renal hemodynamics. Journal of Clinical Investigation, 41, 1922.

Levin, J., Tomasulo, P.A. \& Oser, R.S. (1970) Detection of endotoxin in human blood and demonstration of an inhibitor. Journal of Laboratory and Clinical Medicine, 75, 903.

LeVY, V.G. (1972) Correspondence. Gastroenterology, 63, 199.

LiebermanN, F.L., Reynolds, T.B. (1966) Renal failure with cirrhosis: Observations on the role of diuretics. Annals of Internal Medicine, 64, 1221.

McCloy, R.M., Baldus, W.P., Tauxe, W.N. \& SummerSKILL, W.H.J. (1967) Plasma volume and renal circulatory function in cirrhosis. Annals of Internal Medicine, 66, 307.

PAPPeR, S. \& VAamonde, C.A. (1971) The kidney in liver disease. In: Disease of the Kidney (Ed. by M. B. Strauss and L. G. Welt), p. 1139. Little, Brown, Boston.

Reynolds, T.B., Lieberman, F.L. \& Redeker, A.G. (1967) Functional renal failure with cirrhosis: the effect of plasma expansion therapy. Medicine (Baltimore), 46, 191.

Shear, L., Kleinerman, J. \& Gabuzda, G.J. (1965) Renal failure in patients with cirrhosis of the liver. American Journal of Medicine, 39, 184.

Schroeder, E.T., Numann, P.J. \& Chamberlain, B.E. (1970). Functional renal failure in cirrhosis: recovery after portacaval shunt. Annals of Internal Medicine, 72, 923.

VESIN, P. (1962) Late functional renal failure in cirrhosis with ascites. In: Aktuelle Probleme der Hepatologie: Ultrastruktur, Steroidstoffwechsel, Durchblutung, Leber und Niere. (Ed. by G. A. Martini and S. Sherlock), p. 98. Georg Thieme Verlag, Stuttgart.

WARDLE, E.N. (1974) Endotoxaemia in liver disease. Lancet, i, 930 .

Wilkinson, S.P., Arroyo, V., Gazzard, B.G., Moodie, H. \& WILliams, R. (1974a) Relation of renal impairment and haemorrhagic diathesis to endotoxaemia in fulminant hepatic failure. Lancet, i, 521 .

Wilkinson, S.P., Blendis, L.M. \& Williams, R. (1974b) Frequency and type of renal and electrolyte disorders in fulminant hepatic failure. British Medical Journal, 1, 186. 